University of Wollongong

Research Online

Faculty of Business - Papers (Archive)

Faculty of Business and Law

$1-1-2016$

Differential responses of loyal versus habitual consumers towards mobile site personalization on privacy management

Hyunjin Kang

George Washington University, huk142@psu.edu

Wonsun Shin

Nanyang Technological University

Wing Yin Leona Tam

University of Wollongong, Itam@uow.edu.au

Follow this and additional works at: https://ro.uow.edu.au/buspapers

Part of the Business Commons

Research Online is the open access institutional repository for the University of Wollongong. For further information contact the UOW Library: research-pubs@uow.edu.au 


\title{
Differential responses of loyal versus habitual consumers towards mobile site personalization on privacy management
}

\author{
Abstract \\ We examine how two different underlying mechanisms of behavioral loyalty to a brand - attitudinal loyalty \\ and habit - impact smartphone users' privacy management when they browse personalized vs. non- \\ personalized mobile websites. The online experimental study conducted with Amazon Mechanical Turk \\ workers $(\mathrm{N}=73)$ finds different responses of attitudinal loyalty and habit towards personalization in \\ significant three-way interactions between personalization, attitudinal loyalty, and habit on privacy \\ disclosure and protection behaviors. When interacting with a personalized website, highly habitual \\ consumers without high level of attitudinal loyalty disclosed the most personal information on a \\ personalized mobile site, and displayed the least intention of protecting their privacy on their \\ smartphones, whereas consumers with high levels of both habit and attitudinal loyalty reported the \\ highest tendency of privacy protection behavior. However, habit and personalization do not have a \\ significant effect on disclosure behaviors when users have high attitudinal loyalty to a brand. Theoretical \\ and practical implications are discussed.
}

\section{Keywords}

loyal, versus, habitual, consumers, towards, mobile, responses, site, differential, personalization, privacy, management

\section{Disciplines \\ Business}

\section{Publication Details}

Kang, H., Shin, W. \& Tam, W. (2016). Differential responses of loyal versus habitual consumers towards mobile site personalization on privacy management. Computers in Human Behavior, 56 281-288. 
Full length article

\title{
Differential responses of loyal versus habitual consumers towards mobile site personalization on privacy management
}

\author{
Hyunjin Kang ${ }^{\text {a, * }}$, Wonsun Shin ${ }^{b}$, Leona Tam ${ }^{c}$ \\ a The Center for the Connected Consumer, The George Washington University, School of Business, 2201 G Street NW, Washington, DC 20052, USA \\ ${ }^{\mathrm{b}}$ Wee Kim Wee School of Communication and Information, Nanyang Technological University, 31 Nanyang Link, 637718, Singapore \\ c School of Management, Operation and Marketing, Faculty of Business, University of Wollongong, NSW 2500, Australia
}

\section{A R T I C L E I N F O}

\section{Article history:}

Received 14 July 2015

Received in revised form

4 November 2015

Accepted 11 November 2015

Available online 14 December 2015

\section{Keywords:}

Mobile privacy

Personalization

Loyalty and habit

Privacy concern and protection

\begin{abstract}
A B S T R A C T
We examine how two different underlying mechanisms of behavioral loyalty to a brand-attitudinal loyalty and habit-impact smartphone users' privacy management when they browse personalized vs. non-personalized mobile websites. The online experimental study conducted with Amazon Mechanical Turk workers $(\mathrm{N}=73)$ finds different responses of attitudinal loyalty and habit towards personalization in significant three-way interactions between personalization, attitudinal loyalty, and habit on privacy disclosure and protection behaviors. When interacting with a personalized website, highly habitual consumers without high level of attitudinal loyalty disclosed the most personal information on a personalized mobile site, and displayed the least intention of protecting their privacy on their smartphones, whereas consumers with high levels of both habit and attitudinal loyalty reported the highest tendency of privacy protection behavior. However, habit and personalization do not have a significant effect on disclosure behaviors when users have high attitudinal loyalty to a brand. Theoretical and practical implications are discussed.
\end{abstract}

๑) 2015 Elsevier Ltd. All rights reserved.

\section{Introduction}

Use of mobile technology has become pervasive among current consumers. A recent survey showed that about 90 percent of adults in the U.S. have their own cell phones, and 60 percent of them are smartphone users (Pew Research Center, 2014). Due to the prevalence of smartphones among current consumers, mobile interfaces have become one of the major channels through which advertisers reach their target consumers. New mobile technologies enable marketers and advertisers to target individual mobile consumers using promotional messages and content tailored to the individuals' needs and situations such as current locations and personal preferences, a practice called "personalization." Personalization has long been understood to produce positive responses, such as positive attitude (Kalyanaraman \& Sundar, 2006), higher response rates (Howard \& Kerin, 2004), and better message recall (Burnkrant \& Rao Unnava, 1995). However, given that effective personalization depends on marketers' ability to collect data

\footnotetext{
* Corresponding author.

E-mail addresses: hjkang@gwu.edu (H. Kang), wshin@ntu.edu.sg (W. Shin), ltam@uow.edu.au (L. Tam).
}

from mobile users, privacy-related issues are significant downsides of personalization (e.g., Chellappa \& Sin, 2005; Xu, Luo, Carroll, \& Rosson, 2011). Therefore, the effects of personalization on users' information disclosure and protection behaviors are worthy of investigation.

Based on communication privacy management theory (CPM; Petronio, 2002), the current study proposes that consumers develop their own privacy rules to determine their privacy boundaries with each brand based on their relationships with the brand. We propose that brand loyalty and habit are important factors that determine consumers' decisions about where to place these boundaries between the self and the mobile interface when interacting with personalized versus non-personalized mobile brand content.

\section{Literature review}

\subsection{Personalization on mobile services and privacy}

As the term "smartphone" connotes, the functions of advanced mobile devices go beyond those of traditional phones. Portable broadband technology lets us communicate and access information 
and social networks anytime and anywhere, thereby making our lives smarter and easier. In the context of e-commerce, smartphones have dramatically changed consumer behavior, affecting the ways people search and acquire product information, make purchase decisions, and share consumption experiences (Salehan \& Negahban, 2013).

The pervasiveness of mobile devices provides marketers with abundant opportunities to offer value-added services to consumers. One of the key components of current mobile advertising and marketing practices is personalization (Montgomery \& Smith, 2009). Personalization refers to individualized services, products, or content that are tailored to individual users' preferences or interests learned by an adaptive system (Ho, 2006). Marketers can now offer more precisely tailored personalization using mobile technologies, which track and collect richer and more diverse information from their target consumers. Location tracking and behavioral targeting technologies are some examples prevalent in current mobile marketing. Such technologies enable marketers to collect extensive customer information, such as demographic, geographic, and real-time activity information (Park \& Jang, 2014).

Because personalized offerings are based on individual consumers' interests and preferences, personalization is expected to provide added value to consumers, thereby generating positive responses from them. In the persuasion literature, personalized messages have been found to yield higher response rates (Howard \& Kerin, 2004), greater message recall (Burnkrant \& Rao Unnava, 1995), higher behavioral compliance (e.g., Abrahamse, Steg, Vlek, $\&$ Rothengatter, 2007), and more positive responses (Noar, Harrington, \& Aldrich, 2009). Personalization of media interfaces has also been found to produce positive responses. For instance, studies show that Internet users have more positive attitudes toward personalized web portal sites (Kalyanaraman \& Sundar, 2006) and online shopping websites (Sundar, Kang, Wu, Go, \& Zhang, 2013) than non-personalized ones.

However, given that personalized offerings accessed via mobile technology can be created only when marketers have access to individual users' relevant information, including location data, realtime activities, or profile information, personalization may signal permeability of users' privacy boundaries (Sundar et al., 2013). This can lead consumers to be concerned about their privacy when they receive personalized content or services from advertisers.

Overall, the literature suggests that personalization is a doubleedged sword, with both perceived benefits from the information and services that are tailored to the individual user, and perceived risks associated with the personalization process (Xu et al., 2011). Studies found that the perceived benefits of personalization increase a person's likelihood of using personalized online services and of disclosing information on personalized mobile interfaces (Chellappa \& Sin, 2005). However, privacy concerns triggered by content personalization are a negative predictor of consumers' intentions to use online personalization services (Chellappa \& Sin, 2005) as well as to willingness to share information on a mobile interface with personalization features (Xu et al., 2011). It appears that privacy disclosure behaviors on personalized mobile interfaces are based on consumers' assessment and comparison of perceived benefits and risks of disclosing information on personalized interfaces.

\subsection{Communication privacy management theory}

Given that many privacy-related issues are now generated by interactive media technologies, many communication scholars apply communication privacy management theory (CPM; Petronio, 2002) to explain the tension between privacy disclosure and protection in various communication contexts mediated by technologies, including the internet (e.g., Stanton \& Stam, 2003; West \& Turner, 2004). CPM posits that individuals tend to develop their own rules about whether or not to reveal private information in order to effectively manage their privacy. Based on these rules, individuals apply different levels of privacy boundaries in different contexts, ranging from thin-or "porous filters"-to thick, "impenetrable barriers that shield deep, dark secrets" (Petronio, 2002, p. 168).

That is, individuals manage their privacy by deciding where to place the border to divide information into not-to-share or to-share categories. The underlying proposition of this type of decision is that individuals perceive both risks and benefits of privacy or disclosure. For instance, disclosure may be helpful for relationship development or self-expression. CPM also explains that an information owner may experience boundary turbulence when the person detects that a privacy boundary was unexpectedly porous, such that others outside of the privacy boundary had access to private information unbeknownst to the owner. In many cases, this turbulence results from failure of information co-owners to adhere to mutually held privacy expectations (Petronio, 2002). This boundary turbulence increases the original owner's perceived risks with regard to trusting the co-owner, and as a result, the original information owner will be more reluctant to share their information with the co-owner in the future.

Based on this idea of CPM, we can postulate that individuals with thick privacy boundaries to a brand or to mobile technology as a whole will be more likely to experience boundary turbulence when they see personalization cues on a brand's mobile site, they will take that as a hint of a porous privacy boundary and may react by refusing to disclose their information on the site to avoid a more porous privacy boundary. However, those with thin boundaries will be less likely to experience boundary turbulence when they encounter personalization cues, making them more likely to expose personal information on the site than those with thicker boundaries.

In order to understand online consumers' privacy disclosure and protection behaviors on mobile interfaces that use personalization technology, we need to understand the factors that impact consumers' decisions about privacy boundaries. CPM posits that people tend to develop different privacy rules in different situations with different relationships. In the current study, we expect that different types of consumers' relationship with a brand (i.e., attitudinal loyalty vs. habit) can affect consumers' privacy management on mobile sites with personalization features.

\subsection{Attitudinal loyalty versus habit}

Much of consumer behaviors are repeated and therefore relationships are formed. However, consumers may develop different relationships with different brands or marketers. Let's say that Tom and Mary go to Subway close to the office regularly for lunch. We can say that they are both valuable customers to Subway for their repeated purchases. However, there are some differences between these two valuable customers. Tom goes to Subway even when he is not working or when the store is not convenient to him, whereas Mary only goes to Subway on days she is at work. Are their relationships with the brand qualitatively the same? Obviously, both of them are profitable customers, and therefore, they are valued by marketers (Tam, Wood, \& Song, 2009). However, studies show that not all repetition stems from the same motivations or results in the same outcomes (Ji \& Wood, 2007; Tam et al., 2009). Repeat purchases and consumption may reflect deliberate decision-making and a continuous preference for and commitment to a brand. Alternatively, consumption can simply be a manifestation of a person's disposition to repeat past behavior without much thought to the purchase. In the marketing literature, the former is known as 
attitudinal loyalty and the latter as habit.

Characterized by repeated and persistent choice of the same brand, both attitudinal loyalty and habit result in high purchase frequency, high spending, and low brand switching (Liu-Thompkins \& Tam, 2013; Wood \& Neal, 2007). From a marketers' point of view, such repeated and persistent consumption and purchasing are linked to desirable outcomes such as high market share and profits (Wood \& Neal, 2007). This makes loyalty- and habit-driven consumers significant market segments.

Because consumers driven by attitudinal loyalty and habits share many common characteristics, marketers often treat the two segments in the same way (Liu-Thompkins \& Tam, 2013). However, scholars suggest that loyalty and habit operate differently. As mentioned earlier, attitudinal loyalty consists of long-held favorable attitudes and positive perceptions of the brand. Consumers' repeat purchases reflect a continued and stable belief in and preference for the brand (Oliver, 1999; Tam et al., 2009). Thus, consumers loyal to a brand are more likely to resist situational or social influences (Liu-Thompkins \& Tam, 2013; Oliver, 1999). On the other hand, habit is shaped by context-response links in memory (Wood \& Neal, 2007). If a person repeats a particular behavior in a consistent setting, the setting becomes a contextual cue and the person develops an association between the behavior and the cue in his/her memory. When the person encounters the contextual cue, the cue automatically triggers an associated behavior, without requiring much guidance from attitudes, goals or preferences (Ji Song, \& Wood, 2007; Lally, van Jaarsveld, Potts, \& Wardle, 2010; Tam et al., 2009; Wood \& Neal, 2007). Habits can be shaped slowly, but once formed, they are quick to activate (Wood \& Neal, 2007). Consumers are more likely to act habitually when they are under time pressure or distracted, with limited self-control resources (Wood \& Neal, 2007). Since habit is built on contextual cues, it can be less resistant than loyalty to situational and social changes, especially changes that limit the availability of the triggering cues.

Because brand loyalty and habit are formed and operate differently, Studies suggest that marketers should implement different strategies to manage the two different consumer segments (LiuThompkins \& Tam, 2013; Tam et al., 2009). Given both loyaltyand habit-driven consumers have strong relationships with the brand, this study examines how brand loyalty and habit influence the way consumers manage privacy in response to personalized mobile content, posing the following research questions.

RQ. How will loyalty- and habit-driven consumers respond to a brand's personalized vs. non-personalized mobile site in their privacy protection and disclosure behaviors?

Drawing from CPM, a communication theory that explains how and why people make decisions about information disclosure, we attempted to examine how consumers' relationships with a brand impact consumers' private information disclosure on mobile interfaces with personalization features. From the conceptualization of attitudinal loyalty and habit, which are qualitatively different types of relationships that consumers develop with brands, we expect that consumers would develop different privacy rules based on both brand loyalty and habit. As a result, different levels of brand loyalty and habit would lead to different levels of disclosure behaviors on personalized mobile sites. Also, we expect that mobile users' privacy protection behaviors in the context of smartphone technology will be influenced by the existence of personalization features on the mobile site of a brand, and such impact will be moderated by loyalty and habit with regard to the brand. We, therefore, hypothesize that:

H. A three-way interaction between personalization, attitudinal loyalty and habit with regard to a brand will affect a) information protection and b) disclosure behaviors on the brand's mobile site.

\section{Method}

The purpose of the current study is to examine the relationship between content personalization and consumers' information disclosure and protection behaviors on a brand's mobile website, and how this relationship is moderated by brand loyalty and habit. Therefore, we chose an experimental design that exposed research participants to either a personalized or a non-personalized condition as the manipulated independent variable and measured their loyalty and habit associated with the featured brand as the moderators and strategies they adopted to manage personal data on smartphone as the dependent variables.

\subsection{Manipulation of independent variable}

To increase external validity, we crafted mobile websites for an existing brand, Starbucks Coffee. For personalization condition, we created 24 different versions of mobile websites for Starbucks Coffee that matched each participant's current location (6 mid-sized cities: Boston, Dallas, Indianapolis, Milwaukee, Portland, and San Francisco) and beverage preference (4 types of beverages: Black coffee, Coffee with milk, Tea, and Smoothie and Frappuccino). For city-based personalization, the homepage of each personalized mobile website had a greeting with the city name and images related to the city, and its store locator page displayed contact information for 15 stores in each city, with an interactive map that allowed participants to find the store nearest to their location included. For preference-based personalization, the mobile website displayed a menu tab corresponding to the type of beverage that each participant indicated as the most preferred at the top of the menu section with a personalized message. For example, participants who lived in San Francisco and preferred tea got to see a cityspecific greeting message ("Hello, San Francisco"), images, and a locator displaying 15 Starbuck stores in San Francisco which includes a function to find the nearest store to individual participants' current locations, as well as a message related to their beverage preference (e.g., "Tea, Your Favorite!") at the top of the menu on the mobile site.

For non-personalization condition, we created a generic mobile website that had no specific location- or preference-based features. In the store locator page, participants were provided with a general store locator function that let them search for any store in the U.S. Other than the location- and preference-related features, the personalized and non-personalized sites were identical (see sample visuals in Fig. 1).

\subsection{Procedure}

We recruited participants from Amazon's Mechanical Turk (MTurk) system (www.mturk.com), a crowdsourcing Internet marketplace. Smartphone users residing in six mid-sized cities were eligible to participate in the study. We used M-Turk to recruit participants as it is considered a viable alternative to recruit research subjects for social science research, allowing researchers to access a massive pool of people with diverse background (Mason \& Suri, 2012). We chose mid-sized cities as we wanted the participants to perceive a sufficient level of location-based personalization from our personalized mobile websites. The study was conducted in October 2014.

Our online questionnaire consisted of three parts. The first part assessed the participants' smartphone usage patterns, their loyalty to, and habits associated with, Starbucks Coffee, and beverage preferences. The second part of the questionnaire asked the participants to visit and explore a mobile website using their own smartphones, in which they were randomly assigned to either the 
1) Non-personalized mobile site

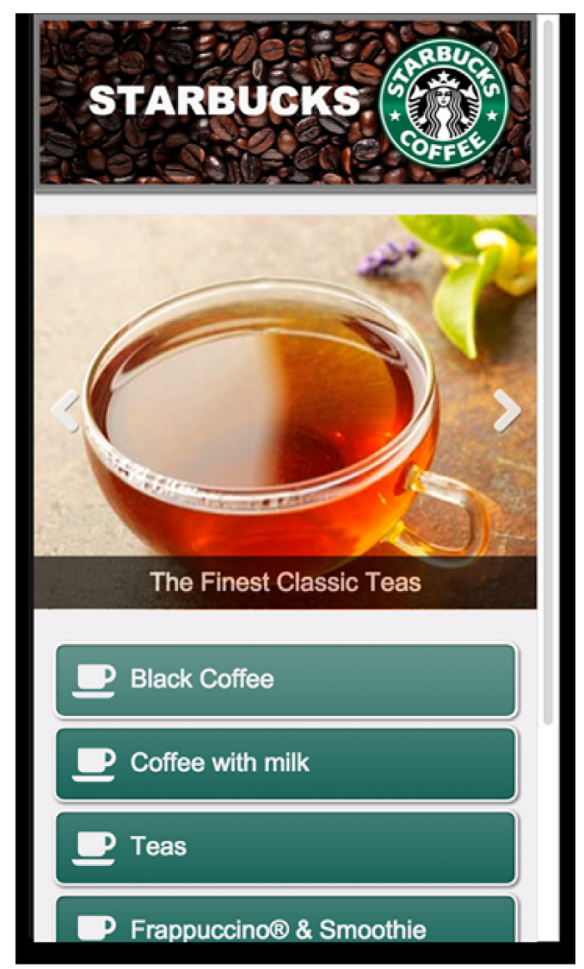

3) Store locator page (personalization condition)

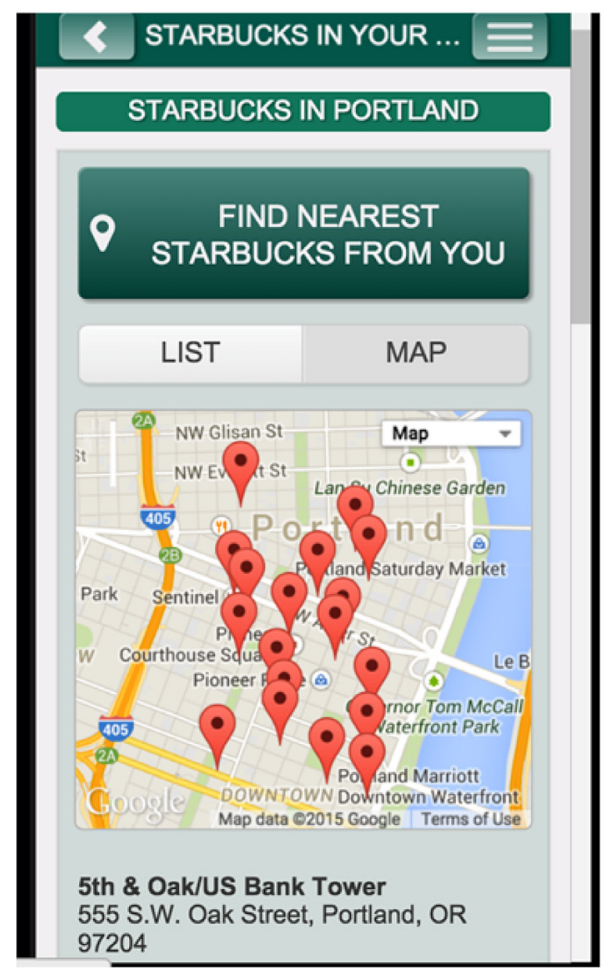

2) Personalized mobile site (preferenceBlack coffee \& location-Milwaukee)

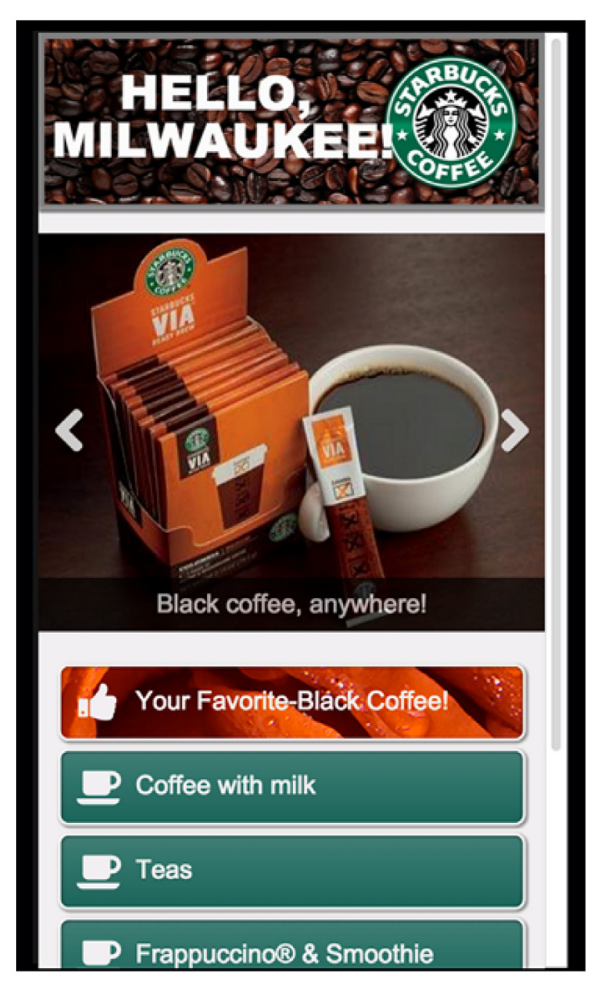

4) Registration page

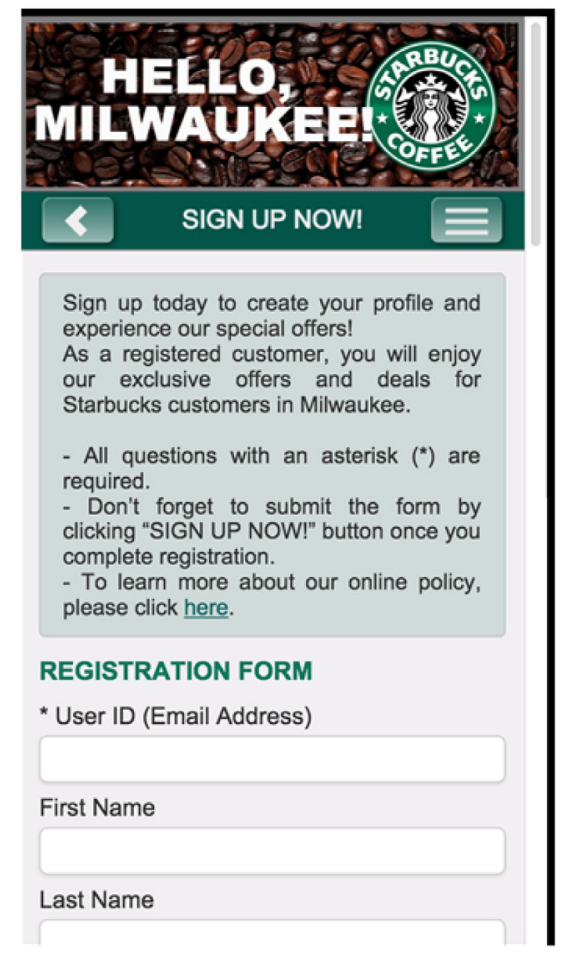

Fig. 1. Stimuli-screenshots of non-personalized vs. personalized versions of mobile sites, and registration page. 
personalized or the non-personalized condition: Those assigned to the personalized condition were directed to a website that matched the beverage preferences they indicated in the first part of the questionnaire and the location (IP) information collected by the online survey program; Those assigned to the non-personalized condition were directed to the generic website. Participants in both conditions were asked to explore the mobile website for at least three minutes and then to register for the site in order to receive promotional information. Upon clicking the submit button on the registration page of the mobile website, participants were asked to return to the online survey site to fill out the third part of the questionnaire, which included measurements for privacy management and protection strategies and collected demographic information.

In total, 73 participants successfully completed the study (personalization condition: $n=38$; control condition: $n=35$ ). 53\% of participants were male and $74 \%$ were Caucasian. $42 \%$ of participants were between 25 and 34, while 22\% were between 35 and 44 . $32 \%$ responded that they used smartphones $4-5 \mathrm{~h}$ per day, and $21 \%$ did so $2-3 \mathrm{~h}$ per day.

\subsection{Measures}

\subsubsection{Attitudinal loyalty}

Participants' attitudinal loyalty to Starbucks Coffee was measured with six 7-point Likert scales (1: Strongly disagree to 7: Strongly agree) adopted from Yi and Jeon (2003) (e.g., "I like Starbucks more than other cafés"; "I would recommend Starbucks to others"; $\alpha=.96$ ).

\subsubsection{Habit}

Participants' habit strength associated with Starbucks Coffee was assessed with twelve 7-point Likert scales (1: Strongly disagree to 7: Strongly agree) by measuring context stability (e.g., "Going to Starbucks belongs to my daily/weekly routine"), action frequency (e.g., "I go to Starbucks frequently"), and automaticity of the behaviors (e.g., "I go to Starbucks automatically") adopted from previous studies on habit (adapted from Liu-Thompkins \& Tam, 2013; Wood, Tam, \& Witt, 2005; Wood, Quinn, \& Kashy, 2002; $\alpha=.95$ ).

\subsubsection{Privacy management on smartphone}

The extent to which participants protect and manage their privacy on their smartphones was measured by asking how often they were engaged in different types of privacy protection behaviors using five 7-point frequency scales (1: Never to 7: Always; e.g., "Decide not to install an app to your smartphone because you found out you would have to share personal information in order to use it") adopted from Boyles, Smith, and Madden (2012).

\subsubsection{Disclosure behaviors}

On the registration site of the mobile website, participants were asked to provide personal information and presented with 14 different types of information commonly collected by online or mobile marketers, including name, address, cell phone number, work phone number, gender, age, hobbies, income, number of credit cards owned, and type of primary credit card. The number of items on the registration page that participants responded to was counted to create the composite scale for disclosure behaviors.

\subsubsection{Manipulation check}

In order to check if our manipulation of personalization was successful, the participants were asked to indicate their agreement with two manipulation check items: "The mobile site was tailored based on my location information," and "The mobile site was tailored based on my beverage preference" using 7-point Likert scale (1: Strongly disagree to 7: Strongly agree).

\section{Results}

\subsection{Manipulation check}

Independent sample $t$-tests revealed that participants in the personalization condition were more likely to report that the mobile sites they interacted with were personalized based on their location, $t(63.68)=8.04, p<.001$, control condition: $M=3.03$, $S D=1.63$; personalization condition: $M=5.79, S D=1.26$, and coffee preference information, $t(70.24)=2.40, p<.01$, control condition: $M=3.83, S D=1.96$; personalization condition: $M=4.92, S D=1.92$. For both tests, equal variances were not assumed based on Levene's test.

\subsection{Testing hypothesis and research question}

Our hypothesis proposed a significant three-way interaction between personalization, brand loyalty, and habit with regard to privacy disclosure and protection behaviors. In order to test the hypotheses, the three factors (personalization condition, brand loyalty, and habit) and all the two-way and three-way interaction terms were regressed with regard to a) privacy disclosure and b) privacy management (protection) behaviors. We found significant three-way interactions on disclosure behaviors $(\beta=.40, p<.05)$ and marginally significant interaction on protection behaviors ( $\beta=-.34, p=.051)$, supporting the hypothesis. See Table 1 for the regression analysis results.

In order to decompose the three-way interaction effects, and to ascertain the direction of the effects of our independent and moderating variables, further analyses were conducted, by splitting brand loyalty into two levels (low: below median; and high: equal to or above median). Results showed that for low-loyalty respondents, habit had a marginal negative effect on disclosure behaviors when the users interacted with a mobile website without personalization features $(\beta=-.44, p=.098)$, whereas habit had a marginal positive impact on disclosure behaviors when the users interacted with a personalized mobile site $(\beta=.43, p=.06)$. However, among high-loyalty respondents, habit did not have significant effects on disclosure behaviors in both control $(\beta=-.02$, $p=.94)$ and personalization conditions $(\beta=-.22, p=.38$; See Fig. 2).

The interaction with regard to protection behaviors was examined using the same methods as for disclosure behaviors. The results show that, for low-loyalty respondents, strength of habit was not significantly associated with privacy protection behaviors on mobile phones when they used a non-personalized mobile site ( $\beta=-.03, p=.91)$, whereas habit had a significant negative effect

Table 1

Summary of multiple regression tests.

\begin{tabular}{|c|c|c|c|c|}
\hline \multirow[t]{2}{*}{ Factors } & \multicolumn{2}{|c|}{$\begin{array}{l}\text { DV: disclosure } \\
\text { behaviors }\end{array}$} & \multicolumn{2}{|c|}{$\begin{array}{l}\text { DV: protection } \\
\text { behaviors }\end{array}$} \\
\hline & $\beta$ & SE & $\beta$ & SE \\
\hline Personalization condition (P) & -.25 & .74 & .22 & .21 \\
\hline Loyalty (L) & $.40^{\mathrm{b}}$ & .42 & .18 & .12 \\
\hline Habit $(\mathrm{H})$ & $-.38^{\mathrm{a}}$ & .56 & -.13 & .16 \\
\hline $\mathrm{P} \times \mathrm{L}$ & $.39^{\mathrm{b}}$ & .42 & -.14 & .12 \\
\hline $\mathrm{P} \times \mathrm{H}$ & $-.46^{\mathrm{b}}$ & .56 & -.07 & .16 \\
\hline $\mathrm{L} \times \mathrm{H}$ & -.03 & .21 & $.31^{\mathrm{b}}$ & .06 \\
\hline $\mathrm{P} \times \mathrm{L} \times \mathrm{H}$ & $.40^{\mathrm{b}}$ & .21 & $-.34^{\mathrm{a}}$ & .06 \\
\hline$R^{2 a d j}$ & .05 & & .06 & \\
\hline
\end{tabular}

a $p<.10$.

b $p<.05$. 
a) Low loyalty (interaction between habit and personalization)

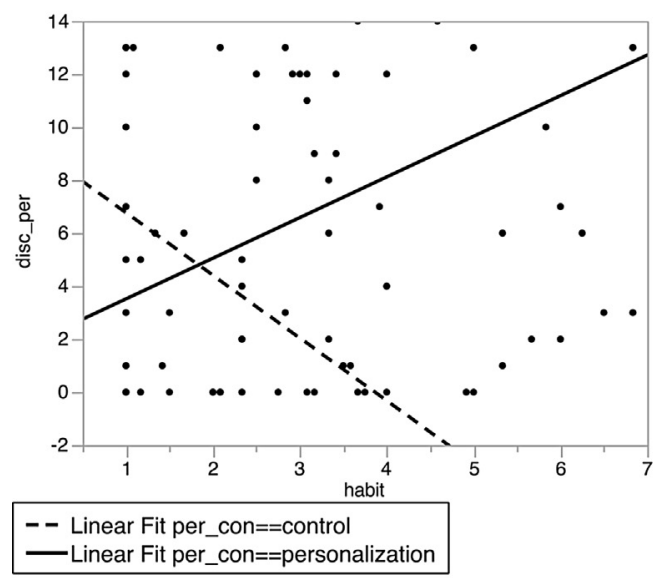

b) Highloyalty (interaction between habit and personalization)

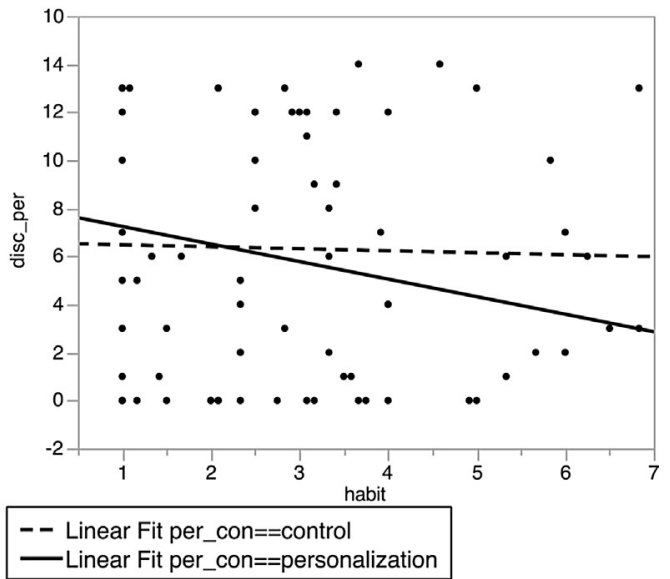

Fig. 2. Interaction patterns (DV: disclosure behaviors).

on privacy protection behaviors $(\beta=-.48, p=.01)$. For the highloyalty respondents, habit did not influence how likely they were to engage in privacy protection behaviors when they interacted with the non-personalized site $(\beta=-.14, p=.56)$. However, strength of habit functioned to increase the level of protection behaviors high-loyalty people used when interacting with a personalized mobile site ( $\beta=.56, p=.02$; See Fig. 3 ).

\section{Discussion}

\subsection{Theoretical implications}

Personalized advertising and promotional content have become important components of marketing communication. An increasing number of advertisers are using mobile advertising as mobile penetration rates continue to grow. Advances in tracking and targeting technologies enable advertisers to understand consumers' contexts and to customize promotional messages based on the needs and preferences of specific target groups. This type of personalization is expected to result in positive outcomes. However, the personalization process itself, which is based on the use of consumers' own personal information, may hinder the effects and effectiveness of the messages.

This study examined two factors-loyalty and habit- as potential moderators of the relationship between personalization of a mobile site and consumers' personal information management behaviors. Based on the literature on brand loyalty and habit, which illustrates qualitative differences between loyalty and habit in terms of their drivers and behavioral outcomes (e.g, Ji \& Wood, 2007; Tam et al., 2009), we expected that brand loyalty and habit would have different effects on users' responses to personalization. Specifically, the study hypothesized that attitudinal loyalty and habit would lead to different levels of privacy disclosure and protection behaviors on a brand's mobile site. We expected that these two relational variables with regard to a brand would function as motivational factors for developing different privacy rules in interactions with the brand's mobile sites.

As we expected, personalization and the two different forms of a) Low-loyalty (interaction between habit and personalization)

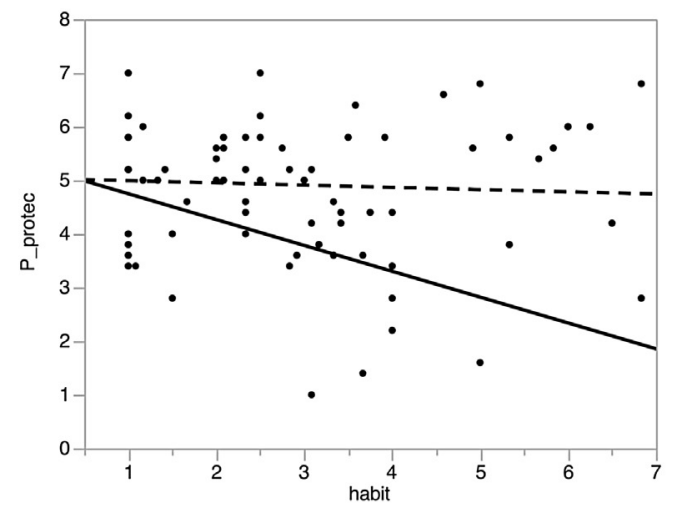

Linear Fit

- - Linear Fit per_con $==$ control - Linear Fit per_con==personalization b) High-loyalty (interaction between habit and personalization)

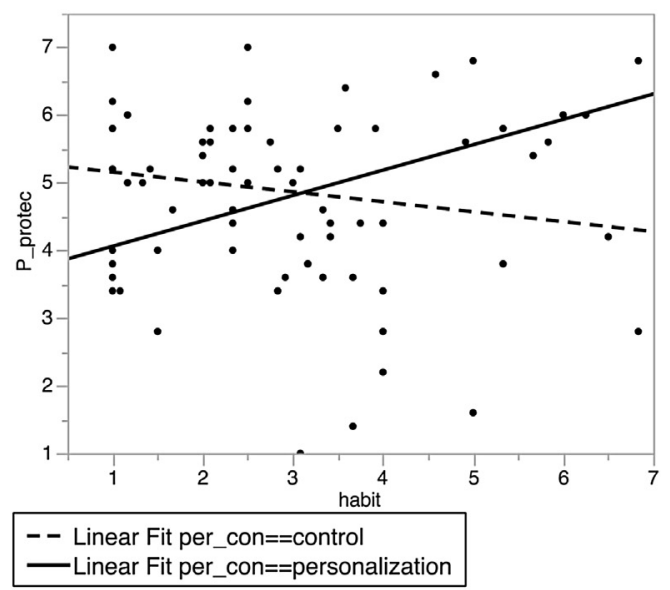

Fig. 3. Interaction patterns (DV: protection behaviors). 
relationships with the brand (i.e., loyalty and habit) interacted with regard to users' privacy-related behaviors while using the brand's mobile site. First of all, this result supports the fact that not all repeat customers are the same (Tam et al., 2009), and these differences can manifest in users' mobile privacy behaviors. More interestingly, personalization features had significant effects on privacy disclosure and protection behaviors when both attitudinal loyalty and behavioral disposition levels were accounted for in the interaction terms. The result signifies that the two types of commitment to a brand (i.e., loyalty and habit) tend to influence a person's privacy boundaries in different ways when the user encounters personalization features or content on the brand's mobile site, potentially inducing 'boundary turbulence' (Petronio, 2002).

The data patterns of three-way interaction (Figs. 2 and 3) yielded interesting implications. We found that habit and personalization conditions interacted to affect disclosure behaviors on a brand's mobile site by users who showed low levels of attitudinal loyalty. However, for users high in brand loyalty, neither the level of habit nor personalized features on the brand's mobile site influenced the level of information disclosure. This result indicates that those who use a brand habitually, rather than because of an attitudinal attachment, are likely to have the strongest motivation to disclose personal information to the brand when they interact with a mobile website that is personalized for them. The interaction pattern with regard to protection behaviors provides a clue with which to interpret this result. For users high on attitudinal loyalty (Fig. 3-b), their level of habitual usage of the brand functioned to increase the likelihood that they would protect their private information when using the mobile technology. Presumably, users with high attitudinal and habitual loyalty are most likely to experience 'boundary turbulence' when they see personalized features. They are the ones who might have had the most motivation to share personal information during previous interactions with the brand (e.g., participating in loyalty programs or promotional events); therefore, personalization cues on the mobile site could have triggered them to be more protective in their current privacyrelated practices using mobile devices and discouraged them from sharing information on the mobile site.

Moreover, the result can be interpreted by applying social penetration theory (SPT; Altman \& Taylor, 1973), which served as a core basis of CPM theory. SPT posits that relationships progress from non-intimate to intimate, and that self-disclosure is the key factor that develops relationships until they reach the stable exchange stage. Applying the core ideas of SPT, we can assume that those who show high attitudinal loyalty to a brand have already established a stable relationship with the brand compared to those who have low attitudinal loyalty. This could be the reason why neither personalization features on the mobile site nor behavioral commitment to the brand had an impact on these users' disclosure behaviors. It must be noted that users high in attitudinal loyalty provided a non-negligible amount of personal information to the mobile site regardless of their level of brand habit and the existence of personalization features on the mobile site. On the other hand, the data indicate that those who habitually use a brand without attitudinal loyalty to it are more motivated than others to develop a closer relationship with the brand when the brand's service recognizes them and provides individually tailored offerings. This might be because they are already committed to the brand on a surface level (i.e., habitual usage), but have not yet had enough opportunities for motivational events leading them to consider the value of the brand, therefore have not yet developed attitudinal loyalty corresponding to their behavioral commitment to the brand.

\subsection{Practical implications}

The current study provides valuable practical implications for marketers, mobile advertisers, and mobile interface designers. First of all, our results indicate that personalized brand content does not always lead customers to be more open to a brand. Instead, personalization on an interactive interface of a certain brand may trigger consumers to be more cautious about their privacy. Such effects can be prominent for those who already have high attitudinal loyalty and behavioral disposition toward the brand (habit), who would be regarded as the most valuable customers for marketers. For those customers, customization, which allows individuals to tailor content and features of the interface, can be a viable alternative to personalization. Users who are highly committed to a brand, in terms of both their attitude and behavior, would already have extensive knowledge of the brand and a clear preference for it. Therefore, they would be capable of dictating how the interactive interface should function in order to cater to their own preferences and interests related to the brand.

However, our results suggest that personalization can be an effective motivational factor that triggers habitual users, who do not have attitudinal loyalty, to develop a closer relationship with the brand via self-disclosure. Therefore, for instance, personalized content or cues in online invitations to loyalty programs can be effective for regular customers who have not yet signed up for the programs. Overall, the study results revealed that personalization does not produce the same effects in all consumers, at least in terms of privacy management, due to the different levels of relationships that users developed with a brand. Thus, providing clear instructions on how to opt out of receiving personalized offerings and clear explanations of how personal information is collected and used can minimize the privacy downside of personalization.

Marketers and advertisers are encouraged to develop a good understanding of the degree to which their target consumers are attached to a brand, especially if the goal of their campaign is to obtain personal information from consumers using mobile content to generate leads or build a consumer database. Depending on consumers' attitudinal loyalty and behavioral disposition to a brand, some advertisers' efforts catering to individual needs through personalization technology can backfire, resulting in users avoiding disclosing themselves to the brand, which is crucial for a successful interactive communication between a brand and its customers.

\subsection{Limitations and future research}

Although the current study has valuable implications, certain limitations should not be ignored. Our study examined privacy disclosure and protection behaviors of participants right after a one-time exposure to a personalized or non-personalized mobile site. Using personalized services for a long period of time, as opposed to a one-time usage, may elicit different consequences. Therefore, future studies can employ a longitudinal approach to explore the effects of personalization of a brand's mobile interfaces on privacy-related perceptions and behaviors among consumers.

In addition, the study employed two types of personalization-personalization based on location and on the preferences of individual users. However, there are other types of personal information that can be used as a basis for personalization, such as affiliation, social and personal identities, and browsing history. Future studies can further explore the effects of various types of personalization based on different types of user information. In addition, because the main purpose of our study was to examine the effects of personalization practices prevalent in current mobile services on users' privacy-related behaviors, the 
current study was not designed to dissect whether the effects of personalization on privacy-related behaviors are derived from location-based or preference-based personalization. Therefore, future studies exploring the effect of each type of personalization (e.g. location vs. preference) on privacy concerns or disclosure behaviors will provide useful implications, particularly for mobile interface designers.

\section{References}

Abrahamse, W., Steg, L., Vlek, C., \& Rothengatter, T. (2007). The effect of tailored information, goal setting, and tailored feedback on household energy use, energy-related behaviors, and behavioral antecedents. Journal of Environmental Psychology, 27(4), 265-276.

Altman, I., \& Taylor, D. A. (1973). Social penetration: the development of interpersonal relationships. New York: Holt, Rinehart, \& Winston. Berger.

Boyles, J. L., Smith, A., \& Madden, M. (2012). Privacy and data management on mobile devices. Pew Internet \&American Life Project, September 5, 2012, Available at http://pewinternet.org/Reports/2012/Mobile-Privacy.aspx.

Burnkrant, R. E., \& Rao Unnava, H. (1995). Effects of self-referencing on persuasion. Journal of Consumer Research, 22, 17-26.

Chellappa, R. K., \& Sin, R. G. (2005). Personalization versus privacy: an empirical examination of the online consumer's dilemma. Information Technology and Management, 6(2-3), 181-202.

Ho, S. Y. (2006). The attraction of internet personalization to web users. Electronic Markets, 16(1), 41-50.

Howard, D. J., \& Kerin, R. A. (2004). The effects of personalized product recommendations on advertisement response rates: the "Try This. It works!" technique. Journal of Consumer Psychology, 14(3), 271-279.

Ji Song, M., \& Wood, W. (2007). Purchase and consumption habits: not necessarily what you intend. Journal of Consumer Psychology, 17(4), 261-276.

Kalyanaraman, S., \& Sundar, S. S. (2006). The psychological appeal of personalized content in web portals: does customization affect attitudes and behavior? Journal of Communication, 56(1), 110-132.

Lally, P., van Jaarsveld, C. H. M., Potts, H. W. W., \& Wardle, J. (2010). How are habits formed? Modelling habit formation in the real World. European Journal of Social Psychology, 40(6), 998-1009.

Liu-Thompkins, Y., \& Tam, L. (2013). Not all repeat consumers are the same: designing effective cross-selling promotion on the basis of attitudinal loyalty and habit. Journal of Marketing, 77, 21-36.

Mason, W., \& Suri, S. (2012). Conducting behavioral research on Amazon's
Mechanical Turk. Behavior Research Methods, 44(1), 1-23.

Montgomery, A., \& Smith, M. D. (2009). Prospects for personalization on the internet. Journal of Interactive Marketing, 23(2), 130-137.

Noar, S. M., Grant Harrington, N., \& Aldrich, R. S. (2009). The role of message tailoring in the development of Persuasive health communication messages. In C. S. Beck (Ed.), Communication yearbook 33 (pp. 73-133). New York, NY: Routledge.

Oliver, R. L. (1999). Whence consumer loyalty? Journal of Marketing, 63(Special Issue), 33-44.

Park, Y. J., \& Jang, S. M. (2014). Understanding privacy knowledge and skill in mobile communication. Computers in Human Behavior, 38, 296-303.

Petronio, S. (2002). Boundaries of privacy: dialectics of disclosure. Albany, NY: State University of New York Press.

Pew Research Center. (2014). Mobile technology fact sheet. Available at http://www pewinternet.org/fact-sheets/mobile-technology-fact-sheet Accessed 25.10.14.

Salehan, M., \& Negahban, A. (2013). Social networking on smartphones: when mobile phones become addictive. Computers in Human Behavior, 29, 2632-2639.

Stanton, J.,M., \& Stam, K. R. (2003). Information technology, privacy, and power within organizations: a view from boundary theory and social exchange Perspectives. Surveillance \& Society, 1(2), 152-190.

Sundar, S. S., Kang, H., Wu, M., Go, E., \& Zhang, B. (2013). Unlocking the privacy paradox: do cognitive heuristics hold the key?. In Proceedings of the 2013 Annual Conference on Human Factors in Computing systems (CHI'13) (pp. 811-816).

Tam, L., Wood, W., \& Song, M. J. (2009). Brand loyalty is not habitual. In D. J. Maclnnis, C. Whan Park, \& J. R. Priester (Eds.), Handbook of brand relationships (pp. 43-62). Armonk,NY: M.E.Sharpe.

West, R., \& Turner, L. (2004). Introducing communication theory: analysis and application (2nd ed.). Boston: McGraw-Hill.

Wood, W., \& Neal, D. T. (2007). The habitual consumer. Journal of Consumer Psychology, 19(4), 579-592.

Wood, W., Quinn, J. M., \& Kashy, D. A. (2002). Habits in everyday life: thought emotion, and action. Journal of Personality \& Social Psychology, 83(6) 1281-1297.

Wood, W., Tam, L., \& Witt, M. G. (2005). Changing circumstances, disrupting habits. Journal of Personality and Social Psychology, 88(6), 918-933.

Xu, H., Xin, L., Carroll, J. M., \& Rosson, M. B. (2011). The personalization privacy paradox: an exploratory study of decision making process for location-aware marketing. Decision Support Systems, 51(1), 42-52.

Yi, Y., \& Jeon, H. (2003). Effects of loyalty programs on value perception, program loyalty, and brand loyalty. Journal of the Academy of Marketing Science, 31(3), 229-240. 